\title{
Threshold Conditions for a Non-Autonomous Epidemic System Describing the Population Dynamics of Dengue*
}

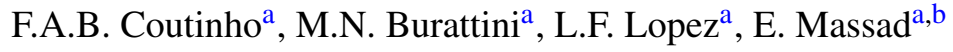 \\ ${ }^{a}$ School of Medicine, The University of São Paulo and LIM 01/HCFMUSP, \\ Av. Dr. Arnaldo 455, São Paulo CEP 01246-903, SP, Brazil \\ ${ }^{b}$ London School of Hygiene and Tropical Medicine, London University, London, UK
}

Published online: 30 June 2007

(c) Society for Mathematical Biology 2007

In the html abstract portion of the online publication of "Threshold Conditions for a NonAutonomous Epidemic System Describing the Population Dynamics of Dengue" (DOI: 10.1007/s11538-006-9108-6) the last names of the authors were erroneously misspelled. The authors' names should have appeared as above. Springer regrets the errors.

\footnotetext{
*The online version of the original article can be found at http://dx.doi.org/10.1007/s11538-006-9108-6.
} 